\title{
ФЕНОЛОГИЯ ГНЕЗДОВОГО ПЕРИОДА СЕМЕЙСТВ ДРОЗДОВЫХ И ВРАНОВЫХ НА ТЕРРИТОРИИ АЛТАЙ-САЯНСКОГО ЭКОРЕГИОНА
}

\section{PHENOLOGY OF THE NESTING PERIOD OF DROZDOVA AND VRANOVA FAMILIES IN THE TERRITORY OF THE ALTAI-SAYAN ECOREGION}

\section{R. Asmolova}

A. Degtyarenko

Summary. Due to the mosaic nature of conditions, the diversity of the living environment and the selectivity of certain species to it, a high level of bird biodiversity is noted on the territory of the Altai-Sayan ecoregion (Central Siberian part). For a detailed analysis of the peculiarities of nesting and distribution, we have selected the most common species, the abundance of which is numerous (10-99 individuals / $\mathrm{km2}$ ), or very numerous (100 or more individuals / km2). Accordingly, we have identified the following representatives: song thrush (Turdus philomelos Brehm.); red-browed (Turdus iliacus L.); black-throated thrush (Turdus atrogularis Jarocki); olive thrush (Turdus obscurus Gmel.); deer (Turdus viscivorus L.); fieldfare (Turdus pilaris L.); red-throated thrush (Turdus ruficollis R.).

Keywords: Altai-Sayan ecoregion, biodiversity of birds, nesting, phenology, distribution, abundance, Blackbirds, Corvids.

\author{
Асмолова Рузанна Ахмедгарифовна \\ Aспирант, ФГБОУ ВО «Красноярский \\ государственный педагогический университет \\ им. В.П. Астафьева», г. Красноярск \\ ryzanka2010@mail.ru \\ Дегтяренко Анна Юрьевна \\ Аспирант, ФГБОУВО «Красноярский \\ государственный педагогический университет \\ им. В.П. Астафьева», г. Красноярск
}

Аннотация. Благодаря мозаичности условий, разнообразию среды жизни и избирательности к ней отдельных видов на территории Алтай-саянского экорегиона (среднесибирская часть) отмечается высокий уровень биоразнообразия птиц. Для детального анализа особенностей гнездования и распространения нами были выбраны наиболее распространенные виды, обилие которых многочисленно (10-99 особей/ км2), или очень многочисленно (100 и более особей/ км2). Соответственно, нами были выделены следующие представители: певчий дрозд (Turdus philomelos Brehm.); белобровик (Turdus iliacus L.); чернозобый дрозд (Turdus atrogularis Jarocki); оливковый дрозд (Turdus obscurus Gmel.); деряба (Turdus viscivorus L.); рябинника (Turdus pilaris L.); краснозобый дрозд (Turdus ruficollis P.).

Ключевые слова: Алтай-Саянский экорегион, биоразнообразие птиц, гнездование, фенология, распространение, обилие, Дрозды, Врановые.

ся около 97 видов птиц, которые представляют интерес в качестве особо охраняемых на территории РФ на федеральном и региональном уровнях. Все это позволяет заключить, что Алтай-Саянский регион может рассматриваться в качестве особо ценных территорий. Большой вклад данного региона в дело сохранения генофонда исчезающих и редких птиц. Регион имеет важное значение для сохранения биоразнообразия как на территории РФ, так и в мире в целом.

Именно по этой причине данный регион был включен в список «Global-200». В данный список, в соответствии с указаниями Всемирного Фонда дикой природы (WWF) попадают девственные и малоосвоенные территории мира, включающие свыше 90\% биоразнообразия планеты.

В настоящее время все больше внимания уделяется изучению биологического разнообразия, его сохранению. Это связано с тем, что именно биоразнообразие является гарантом сохранения буферности биосферы и стабильности среды обитания. Поэтому одной из актуальных задач остается инвентаризация биоразноо- 
Таблица 1

\begin{tabular}{|c|c|c|}
\hline № п.п. & Представитель & Характеристика \\
\hline \multicolumn{3}{|c|}{ Семейство Врановые Corvidae } \\
\hline 1 & Кукша Perisoreus infaustus & $\begin{array}{l}\text { Гнездящийся вид, обитающий в зимний период. Частота гнездования - } \\
\text { обычная. Обилие обычное (1-9 особей на км²). }\end{array}$ \\
\hline 2 & Сойка Garrulus glandarius & $\begin{array}{l}\text { Гнездящийся вид, обитает в зимний период. Частота гнездования - низкая. } \\
\text { Обилие - редкий }(0,1-0,9 \text { особей/ км²). }\end{array}$ \\
\hline 3 & Сорока Pica ріса & $\begin{array}{l}\text { Гнездящийся вид, обитает в зимний период. Частота гнездования высокая. } \\
\text { Обилие - многочисленный (10-99 особей/ км²). }\end{array}$ \\
\hline 4 & Кедровка Nucifraga caryocatactes & $\begin{array}{l}\text { Гнездящийся вид, обитает в зимний период. Частота гнездования высокая. } \\
\text { Обилие - многочисленный (10-99 особей/ км²). }\end{array}$ \\
\hline 5 & Клушица Pyrrhocorax pyrrhocorax & $\begin{array}{l}\text { Гнездящийся вид, обитает в зимний период. Частота гнездования высокая. } \\
\text { Обилие - ОР - очень редкий (менее 0,1 особей/ км²). }\end{array}$ \\
\hline 6 & Альпийская галка Pyrrhocorax graculus & $\begin{array}{l}\text { Гнездящийся вид, обитает в зимний период. Частота гнездования высокая. } \\
\text { Обилие - Р -редкий }(0,1-0,9 \text { особей/ км²). }\end{array}$ \\
\hline 7 & Галка Corvus monedula & $\begin{array}{l}\text { Гнездящийся вид, обитает в зимний период. Частота гнездования высокая. } \\
\text { Обилие ОР - очень редкий (менее 0,1 особей/ км²). }\end{array}$ \\
\hline 8 & Даурская галка Coloeus dauuricus & $\begin{array}{l}\text { Гнездящийся вид, обитает в зимний период. Частота гнездования высокая. } \\
\text { Обилие - Р -редкий }(0,1-0,9 \text { особей/ км²). }\end{array}$ \\
\hline 9 & Грач Corvus frugilegus & $\begin{array}{l}\text { Пролетный вид. Встречается летом, но размножение не доказано. Обилие - } \\
\text { P-редкий }(0,1-0,9 \text { особей/ км²). }\end{array}$ \\
\hline 10 & Черная ворона Corvus corone & $\begin{array}{l}\text { Гнездящийся вид, обитающий в зимний период. Частота гнездования - } \\
\text { обычная. Обилие обычное (1-9 особей на км²). }\end{array}$ \\
\hline 11 & Bopon Corvus corax & $\begin{array}{l}\text { Регулярно залетный вид, гнездящийся. Обитает в зимний период. Обилие } \\
\text { обычное (1-9 особей на км²). }\end{array}$ \\
\hline \multicolumn{3}{|c|}{ Семейство Дрозды Turdus } \\
\hline 12 & Певчий дрозд (Turdus philomelos Brehm.) & $\begin{array}{l}\text { Гнездящийся вид. Обитает в зимний период. ОМ — очень многочисленный } \\
(100 \text { и более особей/ км²). }\end{array}$ \\
\hline 13 & Белобровик (Turdus iliacus L.) & $\begin{array}{l}\text { Гнездящийся вид. Обитает в зимний период. ОМ — очень многочисленный } \\
(100 \text { и более особей/ км²). }\end{array}$ \\
\hline 14 & $\begin{array}{l}\text { Чернозобый дрозд (Turdus atrogularis } \\
\text { Jarocki) }\end{array}$ & $\begin{array}{l}\text { Встречаются как пролетные, так и гнездящиеся виды. Пролетные встречаются } \\
\text { редко. Гнездящиеся - очень многочисленны (100 и более особей/ км²). }\end{array}$ \\
\hline 15 & Оливковый дрозд (Turdus obscurus Gmel.) & $\begin{array}{l}\text { Встречаются как пролетные, так и гнездящиеся виды. Пролетные встречаются } \\
\text { редко. Гнездящиеся - очень многочисленны (100 и более особей/ км²). }\end{array}$ \\
\hline 16 & Деряба (Turdus viscivorus L.) & $\begin{array}{l}\text { Гнездящийся вид. Обитает в зимнее время. Обилие - обычное (1-9 особей } \\
\text { на км²). На отдельных территориях очень многочисленны (100 и более } \\
\text { особей/ км²). }\end{array}$ \\
\hline 17 & Рябинника (Turdus pilaris L.) & $\begin{array}{l}\text { Гнездящийся вид. Обитает в зимнее время. Обилие - обычное (1-9 особей } \\
\text { на км²). На отдельных территориях многочисленны (10-99 особей/ км²). }\end{array}$ \\
\hline 18 & Краснозобый дрозд (Turdus ruficollis P.) & $\begin{array}{l}\text { Гнездящийся вид. Обитает в зимнее время. Обилие - обычное (1-9 особей } \\
\text { на км²). На отдельных территориях многочисленны (10-99 особей/ км²). }\end{array}$ \\
\hline
\end{tabular}

Примечание* Для оценки показателя обилия вида использовали шкалу А.П. Кузякина

бразия, поскольку она дает возможность объективно оценить значимость конкретного региона с целью его дальнейшего сохранения [2]. Это и определило выбор темы исследования.

\section{Цель исслеАования}

Изучить особенности гнездовой биологии основных представителей семейств Дроздов и Врановых на территории Алтай-Саянского экорегиона.

\section{Материалы \\ и мето $\Delta$ ы}

В основу работы положены результаты собственного исследования фенологии птиц семейств Дроздов и Врановых на территории Алтай-Саянского экорегиона. Полевые работы проводились на стационарах в различных точках Алтай-Саянского экорегиона - это республики Тыва, Хакасия, Бурятия, Красноярский край, Иркутская и Кемеровская области, Республика Алтай, северо-за- 
падная Монголия. Территориально арена исследований составила в целом около 600 тыс. км².

Модельными регионами, где проводили основные стационарные работы, были избраны территория Республики Тыва и Минусинская котловина, поскольку в этих межгорных впадинах наиболее широко представлен весь спектр биоразнообразия птиц Алтай-Саянского экорегиона.

При изучении биоразнообразия птиц и их экологии использовались общепринятые методики. Фенология птиц изучалась как при стационарных работах, так и в ходе маршрутных учетов. Фиксировались особенности встреч птиц в осенне-весенний период, находки гнезд, фенология гнездового цикла, особенности появления кладок, птенцов, слеток.

Полученные данные обрабатывались в программе Arc View Gis 3.2 и наносились на снимок Landsat-7, имеющий географическую привязку. На основе GPS и GIS-материалов сформирована геоинформационная база данных, содержащая дистрибутивные карты гнездовых участков изучаемых птиц.

\section{Результаты и обсужАения}

Нами были исследованы особенности распространения представителей семейств Врановые и Дрозды. Результаты представлены в таблице 1.

Для детального анализа особенностей гнездования и распространения нами были выбраны наиболее распространенные виды, обилие которых многочисленно (10-99 особей/ км2), или очень многочисленно (100 и более особей/ км2). Соответственно, нами были выделены следующие представители:

1. Певчий дрозд (Turdus philomelos Brehm.)

2. Белобровик (Turdus iliacus L.)

3. Чернозобый дрозд (Turdus atrogularis Jarocki)

4. Оливковый дрозд (Turdus obscurus Gmel.)

5. Деряба (Turdus viscivorus L.)

6. Рябинника (Turdus pilaris L.)

7. Краснозобый дрозд (Turdus ruficollis P.).

Все они относятся к семейству Дрозды Turdus. Краткий фенологический анализ представлен ниже.

Особенности встреч птиц в осенне-весенний период. Покидает северные широты на зиму. Встречи самок и самцов происходят в конце второй - начале третьей декады апреля. В холодные вёсны прилёт певчих дроздов сдвигается на конец апреля. Весенний прилет продолжается около месяца, носит более массовый характер, чем у других дроздов $[1 ; 5]$.
Находки гнезд. Гнездование приходится на май июль. Большинство молодых певчих дроздов покидают окрестности гнездовых участков вскоре после распадения выводков, причём, в отличие от дроздов других видов, продолжают перемещаться даже во время интенсивной смены ювенального оперения [5].

Фенология гнездового ичикла. Молодёжь преобладает в отловах уже в июне-июле, а к началу сентября полностью прекращают отлавливаться молодые, родившиеся в ближайших окрестностях. Взрослые птицы покидают окрестности своих гнездовых участков гораздо позже. Осенняя миграция певчих дроздов проходит в ночное время со второй половины августа. Особенно интенсивно она идёт в сентябре, и в основном завершается к середине октября; отдельные особи встречаются до начала снегопадов. Судя по отловам, пролёт взрослых птиц проходит на неделю раньше, чем у молодых. Большинство певчих дроздов достигает мест зимовок уже в октябре [5].

Особенности появления кладок. Большое и плотное гнездо свито из сухих стеблей и листьев злаков и осоки, скрепленных липкой землей. Лоток выложен более тонкими травинками и растительными волокнами. В поперечнике гнездо от 12 до 20. а в высоту от 8 до 15 см, размер лотка (7-13) x 6,5 см. Обе птицы вдвоем успевают возвести такое сооружение дней за пять, после чего оно дня два сохнет. В высохшее гнездо самка откладывает 4-7 яиц зеленоватого цвета, с густыми коричневыми пестринами, завитками и пятнышками. Величина яиц около $28,7 \times 21,2$ мм. Полные кладки можно найти с конца апреля до середины мая [4].

Особенности появления птенцуов. Самка дрозда за одну кладку откладывает от 4-7 яиц. Высиживают их в течении 15 дней по очереди самка и самец. Вылупившись, птенцы развиваются очень быстро и уже через несколько недель совершают первый вылет из гнезда на землю [3].

Особенности слеток. Появляются примерно в конце мая - июне. Первые слетки появляются через 14-15 дней после появления птенцов на свет [4].

\section{Выво}

Таким образом, результаты проведенного нами исследования указывают на то, что на территории Алтай-Саянского экорегиона широко распространены различные виды птиц. Их биоразнообразие крайне велико, поскольку это регион с неизмененными девственными ландшафтами. Наиболее распространенными являются представители семейств Врановые и Дрозды. Для детального анализа нами были взяты отдельные пред- 
ставители, обилие которых можно охарактеризовать как многочисленное и очень многочисленное по шкале А.П. Кузякина. Наиболее многочисленными, по результатам проведенного нами анализа, являются представители семейства Дрозды, а именно: певчий дрозд (Turdus philomelos Brehm.); белобровик (Turdus iliacus L.); чернозобый дрозд (Turdus atrogularis Jarocki); оливковый дрозд (Turdus obscurus Gmel.); деряба (Turdus viscivorus L.); рябинника (Turdus pilaris L.); краснозобый дрозд (Turdus ruficollis P.).

\section{ЛИТЕРАТУРЫ}

1. Ассоциация заповедников и национальных парков Алтай-Саянского экорегиона.—Режим доступа: http://altai-sayan.ru/? ELEMENT_ID=8638 (дата 0бращения - 30.10.2020).

2. Баранов А. А. Птицы Алтай-Саянского экорегиона: пространственно-временная динамика биоразнообразия: монография. т. I / под общ. ред. д-ра биол. наук, профессора Ц. 3. Доржиева; Краснояр. гос. пед. ун-т им. В. П. Астафьева.—Красноярск, 2012. — 464 с.

3. Герасимчук А. В. Экологические аспекты гнездования дроздов рода Turdus в условиях Чулымо-Енисейской котловины: дисс. канд. биол. наук.- Красноярск: 2011.- 175 c.

4. Головань В. И. Результаты кольцевания дроздов рода Turdus в Псковской области // Русский орнитологический журнал. — 2013. — № 12 (211). — С. 130135.

5. Х Хохлова Т. Ю. Особенности сезонных миграций певчего дрозда Turdus philomelos в Карелии // Русский орнитологический журнал.— 2008.— T. 17.— № 419. - C. 763-765.

( А Асмолова Рузанна Ахмедгарифовна ( ryzanka2010@mail.ru ), Дегтяренко Анна Юрьевна.

Журнал «Современная наука: актуальные проблемы теории и практики»

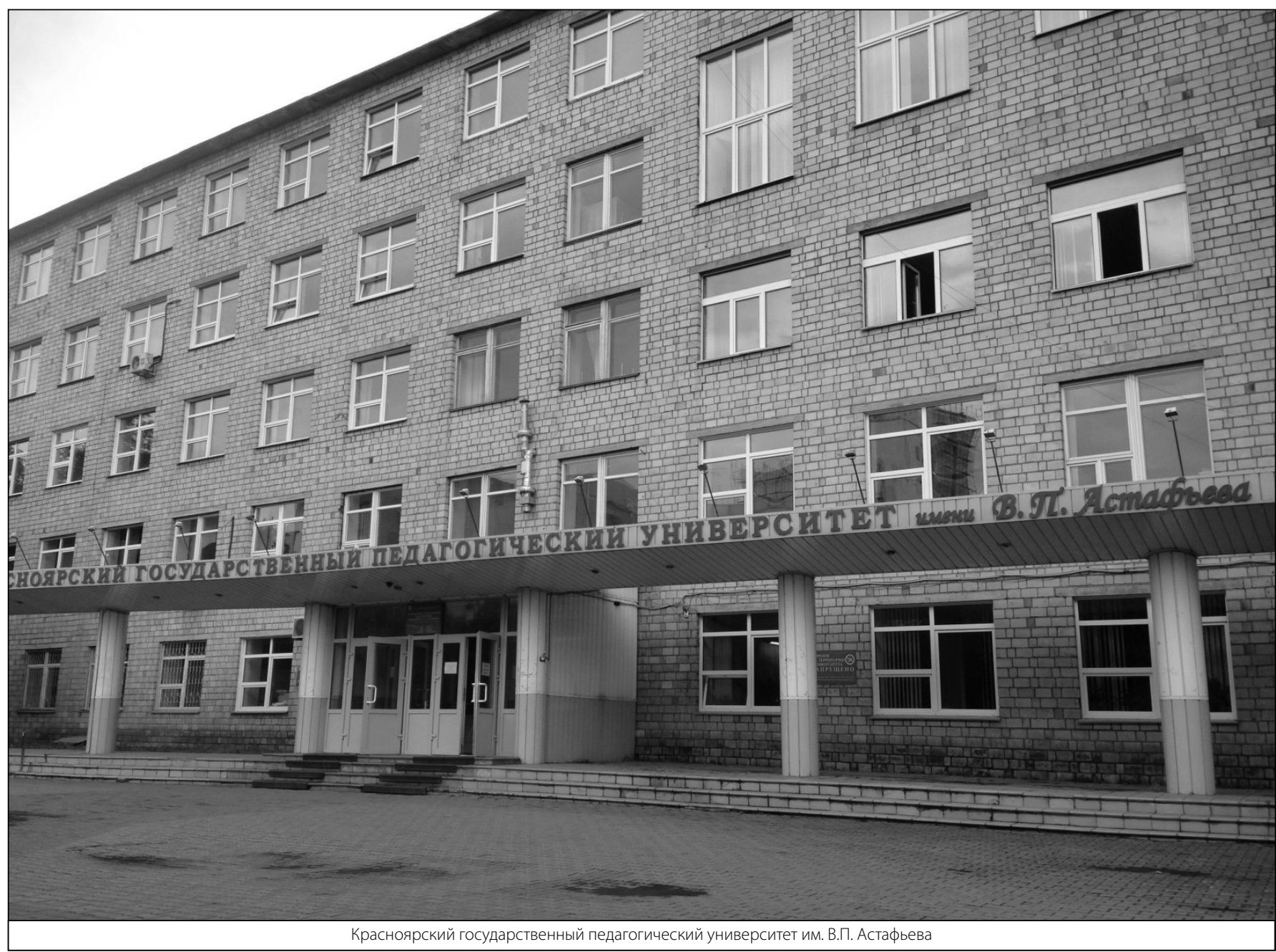

